1 Universidade Estadual de Campinas (Unicamp), Faculdade de Ciências Médicas (FCM) Campinas (SP), Brasil. Associação Brasileira de Saúde Coletiva (Abrasco) - Brasil.

gastaowagner@mpc.com.br

2 Fundação Oswaldo Cruz (Fiocruz), Escola Nacional de Saúde Pública Sergio Arouca (Ensp) - Rio de Janeiro (RJ), Brasil. luciana@ensp.fiocruz.br

3 Universidade Estadual do Oeste do Paraná (Unioeste) - Cascavel (PR), Brasil. Centro Brasileiro de Estudos de Saúde (Cebes) - Brasil. frizon@terra.com.br

4 Universidade Federal Fluminense (UFF), Escola de Serviço Social, Programa de Estudos

Pós-Graduados em Política Social - Niterói (RJ),

Brasil. Centro Brasileiro de Estudos de Saúde (Cebes) - Brasil.

lenauralobato@uol.com.br

5 Fundação Oswaldo Cruz (Fiocruz), Escola Nacional de Saúde Pública Sergio Arouca (Ensp) - Rio de Janeiro (RJ), Brasil. vera@ensp.fiocruz.br

6 Universidade Estadual do Rio de Janeiro (Uerj), Instituto de Medicina Social (IMS) - Rio de Janeiro (RJ), Brasil. rubenm@uol.com.br

\section{Entrevista com o Professor Gastão Wagner de Sousa Campos}

Gastão Wagner de Sousa Campos' ${ }^{\mathbf{1}}$ Luciana Dias de Lima², Maria Lucia Frizon Rizzotto ${ }^{\mathbf{3}}$, Lenaura de Vasconcelos Costa Lobato ${ }^{4}$, Vera Lucia Luiza ${ }^{5}$, Ruben Araújo de Mattos ${ }^{6}$

\section{Introdução}

Gastão Wagner de Sousa Campos é médico sanitarista e professor titular da Universidade Estadual de Campinas. Militante da Reforma Sanitária, Gastão é um defensor intransigente do Sistema Único e Saúde (SUS) e uma referência notória no campo da Saúde Coletiva no Brasil. Em agosto de 2015, durante o XI Congresso Brasileiro de Saúde Coletiva realizado em Goiânia (GO), foi eleita uma nova diretoria da Associação Brasileira de Saúde Coletiva (Abrasco) tendo Gastão como Presidente.

Nessa entrevista, o professor reflete sobre os avanços e os problemas do SUS, bem como os significados da crise atual e os desafios da formação e pesquisa em Saúde Coletiva e na área de Políticas, Planejamento e Gestão em Saúde.

Editoria: Fale brevemente de sua trajetória profissional e dos fatores que motivaram sua atuação no campo da Saúde Coletiva.

Gastão Wagner de Sousa Campos: Fiz graduação em medicina na Universidade de Brasília. O curso era inovador, organizados em blocos interdisciplinares e que combinavam formação teórica e prática. A medicina preventiva e comunitária e a saúde pública ocupavam grande parte de nosso currículo. Tive vários professores que me estimularam a trabalhar no campo do que seria Saúde Coletiva: Carlile Lavour, Henry Jouval, entre outros. Fiz residência em clínica médica e depois fui para a Universidade de São Paulo (USP) fazer especialização em Saúde Pública e mestrado em Medicina Preventiva.

Editoria: Na sua opinião, quais os principais avanços alcançados com a implantação do Sistema Único de Saúde (SUS)?

GW: O principal é a própria existência concreta do SUS, um sistema com grandes problemas, mas que ampliou o direito à saúde. Além da utilidade, o SUS tem exercido um papel simbólico, ao demonstrar a possibilidade e a importância da solidariedade, ao confirmar a necessidade de haver espaço social de não mercado, em que a gestão e o planejamento se orientam a partir das necessidades sociais e não da sobrevivência do mais apto.

Editoria: Que problemas identifica e quais as perspectivas para a universalização efetiva da saúde no Brasil? 
GW: Os principais problemas do SUS são o financiamento inadequado, um modelo de gestão fragmentado, e que tem dificultado o uso intensivo dos recursos existentes, e ainda a inadequada política de pessoal para a saúde, desde a formação até a inexistência de carreira pública. Outro problema é a hegemonia da racionalidade empresarial que tende a invadir o espaço do SUS que deveria funcionar segundo uma racionalidade pública. A perspectiva de avanço do direito à saúde depende da sociedade civil, de nossa capacidade e disposição para defender a existência de políticas públicas e da democracia radical.

Editoria: Como o Sr. está vendo a crise política atual e como ela afeta ou pode afetar a saúde e o SUS?

GW: A crise política atual reflete o acirramento da luta de classes. O capital faz um esforço mundial para resgatar para sua esfera os recursos orçamentários destinados às políticas públicas, por mais desastrosa e cruel seja essa iniciativa. Entretanto, o SUS não se constitui em prioridade para nenhuma das administrações da União desde sua constituição. Ninguém se declara abertamente contra, mas não se observou esforço governamental significativo para consolidação do SUS.

Editoria: Quais os desafios atuais da formação e pesquisa no âmbito da pós-graduação em Saúde Coletiva e, especialmente, na área de Políticas, Planejamento e Gestão em Saúde?

GW: A formação em Saúde Coletiva se ampliou, inclui cursos de graduação, especialização, residência, mestrado profissional e pós-graduação acadêmica (mestrado e doutorado). É urgente a construção de uma carreira para os sanitaristas no SUS, de preferência uma carreira com âmbito nacional, que integre a criação de postos de trabalho nos três âmbitos federativos. A pesquisa em Saúde Coletiva se expandiu nos últimos anos, mas, mesmo assim, se ressente do predomínio de um sistema de gestão e de avaliação com critérios reduzidos de julgamento e com importante grau de exclusão e de concentração de recursos em professores e grupos com suposta excelência.

Editoria: Como vê a importância da Associação Brasileira de Saúde Coletiva (Abrasco) ${ }^{1}$ no contexto atual das políticas de saúde e da pós-graduação?

GW: A Abrasco faz parte do movimento de reforma sanitária. Tem zelado tanto pela construção do direito à saúde e do SUS, quanto de pesquisas e de projetos coletivos, de vigilância e promoção à saúde.

\footnotetext{
1 As principais propostas para a gestão da Abrasco 2015/2018 encontram-se consolidadas no 'Programa para Abrasco 2015: um projeto aberto'. Disponível em: <http://cebes.org. br/2015/07/programapara-abrasco-2015-umprojeto-aberto/>.
} 